\title{
Winter distribution and size structure of Antarctic krill Euphausia superba populations in-shore along the West Antarctic Peninsula
}

\author{
Alison C. Cleary ${ }^{1,2,3, *}$, Edward G. Durbin ${ }^{1}$, Maria C. Casas ${ }^{1}$, Meng Zhou ${ }^{4}$ \\ ${ }^{1}$ Graduate School of Oceanography, University of Rhode Island, Narragansett, Rhode Island 02882, USA \\ ${ }^{2}$ Department of Arctic Biology, University Centre in Svalbard, Longyearbyen, 9171, Norway \\ ${ }^{3}$ Marine Biological Association of the United Kingdom, Plymouth, PL1 2PB, UK \\ ${ }^{4}$ Department of Environment, Earth and Ocean Sciences, University of Massachusetts Boston, Boston, Massachusetts 02125, USA
}

\begin{abstract}
Antarctic krill Euphausia superba are a key component of food webs in the maritime West Antarctic Peninsula, and their life history is tied to the seasonal cycles of sea ice and primary production in the region. Previous work has shown a general in-shore migration of krill in winter in this region; however, the very near-shore has not often been sampled as part of these surveys. We investigated distribution, abundance, and size structure of krill in 3 fjordic bays along the peninsula, and in the adjacent Gerlache Strait area using vertically stratified MOCNESS net tows and ADCP acoustic biomass estimates. Krill abundance was high within bays, with net estimated densities exceeding $60 \mathrm{krill} \mathrm{m}^{-3}$, while acoustic estimates were an order of magnitude higher. Krill within bays were larger than krill in the Gerlache Strait. Within bays, krill aggregations were observed near the seafloor during the day with aggregations extending to the sediment interface, and exhibited diel vertical migration higher into the water column at night. We suggest these high winter krill abundances within fjords are indicative of an active seasonal migration by krill in the peninsula region. Potential drivers for such a migration include reduced advective losses and costs, and availability of sediment food resources within fjords. Seasonally near-shore krill may also affect stock and recruitment assessments and may have implications for managing the krill fishery in this area.
\end{abstract}

KEY WORDS: Euphausiid · Abundance $\cdot$ Diel vertical migration $\cdot$ DVM $\cdot$ WAP $\cdot$ Fjord

\section{INTRODUCTION}

Antarctic krill Euphausia superba (hereafter 'krill') are key members of Southern Ocean ecosystems. Krill serve as important prey to many megafauna; in the West Antarctic Peninsula (WAP) region krill make up over $90 \%$ of the diet of numerous species of baleen whales and the brush-tailed Adélie, gentoo, and chinstrap penguins, and over a third of the diet of additional species of seals, birds, and fish (Quetin \& Ross 1991). These small pelagic crustaceans have a huge global biomass, estimated at over 300 million

\footnotetext{
*Corresponding author: alison_cleary@my.uri.edu
}

tons, with $70 \%$ of the stock found in the Atlantic sector from $0^{\circ}$ to $90^{\circ} \mathrm{W}$, encompassing the WAP (Atkinson et al. 2008).

This huge biomass of krill in the Southern Ocean is not distributed evenly on any spatial scale, with strong patchiness on scales from thousands of kilometers around the continent, to meters within and between aggregations (Hamner \& Hamner 2000, Atkinson et al. 2008, Tarling et al. 2009). Krill are at the 'awkward boundary between plankton and nekton' (Atkinson et al. 2008, p. 2); their distribution can be strongly influenced by current flows, but they are

() The authors 2016. Open Access under Creative Commons by Attribution Licence. Use, distribution and reproduction are unrestricted. Authors and original publication must be credited. 
also strong swimmers, capable of sustained pleiopod swimming speeds of $35 \mathrm{~cm} \mathrm{~s}^{-1}$ and escape velocities in excess of $60 \mathrm{~cm} \mathrm{~s}^{-1}$ (Kils 1981, Hamner 1984).

Much of the research on krill distributions in Antarctica has been focused on the productive and more accessible summer season (Atkinson et al. 2008). A few studies have investigated patterns in the seasonal distributions of krill, both in general and along the WAP. The general paradigm for E. superba in the WAP region has been that krill spend the summer feeding in aggregations along the shelf break and in the waters beyond, with females laying eggs into the deep waters beyond the shelf; while in the fall and winter krill migrate to more in-shore areas (Siegel 1988, Lascara et al. 1999, Nicol 2006, Atkinson et al. 2008). The smallest individuals have generally been found closest in-shore, where they may rely on sea ice for refuge from predation or food resources (Siegel 1988, Lascara et al. 1999, Lawson et al. 2004, Atkinson et al. 2008). The ecological reasons for this migration remain unclear, although it has been suggested it may improve feeding or reduce advection out of the favorable WAP region (Siegel 1988).

Many of the studies that have addressed seasonal variations in krill distribution have observed much lower levels of krill in winter as compared to other seasons. This prominent absence of krill in winter, with early studies indicating winter abundances of just 0.086 krill individuals $\mathrm{m}^{-3}$, an order of magnitude fewer krill than summer, has been termed the winter krill 'vacuum' (Siegel 1988). Later work has continued to provide further evidence of this vacuum; Lascara et al. (1999), sampling broadly over the WAP shelf outside the coastal islands, found krill in winter at just one of their 25 acoustic stations, with total biomass estimates an order of magnitude lower than those in the same region in summer. Seasonal sampling in Marguerite Bay also observed much lower biomass in winter than in fall (Lawson et al. 2004).

Unlike for smaller zooplankton, seasonal changes in observed krill abundance cannot be a result of population growth or contraction. Krill are long lived, taking 2 to 3 yr to reach sexual maturity, with lifespans estimated at 5 to $7 \mathrm{yr}$ (Siegel 1987, Lascara et al. 1999). Additionally, the fall/winter reduction in krill abundance, and corresponding spring increase, is evident in krill from a wide range of sizes (Siegel 1988, Atkinson et al. 2008). Given both the multiyear life cycle of krill, and the parallel abundance patterns amongst different age classes, the seasonal decline and increase in observed krill abundance is more likely to be due to krill entering and exiting the sampled waters. Limited near-shore sampling has suggested this may be where large krill are found in winter (Lawson et al. 2004).

Although krill are thought to move in-shore in winter, the most in-shore regions of the WAP have been poorly sampled, and are missed by the ongoing standardized sampling programs (PalLTER, NOAA AMLR). The coast of the WAP is complex and convoluted, with a series of deep fjordic bays. Vessel and gear safety considerations mean that standardized or randomized transects of the type most often used in broad scale surveys are typically not possible within these areas (Johnston et al. 2012). Sampling within Wilhelmina Bay has shown the presence of krill 'super-aggregations', suggesting this very nearshore region may be important winter habitat for krill (Nowacek et al. 2011).

In this project we used spatially adaptive sampling with nets and acoustics to investigate the distribution, abundance, and size structure of krill within Wilhelmina, Andvord and Flandres Bays and in adjacent comparison areas of the Gerlache Strait in winter. By sampling krill in this poorly known very near-shore region in winter we aimed to refine our understanding of krill seasonal distributions, and the implications of these distributions for the ecology and life history of E. superba in the WAP region.

\section{MATERIALS AND METHODS}

\section{Field collections}

Sampling was carried out on the Research Vessel Ice Breaker Nathaniel B. Palmer between May 16 and June 15, 2013, in Wilhelmina, Andvord and Flandres Bays, in Gerlache Strait outside the bays, and at Palmer Deep further off-shore (Fig. 1, Table 1). Actual sampling locations were fairly tightly constrained based on bathymetry as observed with multibeam sonar, and the need to maintain safe distances from coastlines and large icebergs over a straight line run of $3 \mathrm{~km}$ for MOCNESS towing. At each site, stations consisting of a CTD deployment for hydrography and water collection, a $1 \mathrm{~m}^{2}$ Multiple Opening Closing Net Environmental Sensing System (MOCNESS) (Wiebe et al. 1976, 1985) deployment for krill and larger zooplankton, a vertical tow with a $0.5 \mathrm{~m} 64 \mu \mathrm{m}$ mesh ring net for mesozooplankton and fecal pellets, and a camera deployment for krill observations, were conducted during both day and night. Palmer Deep was sampled only at night due to time and weather limitations. 


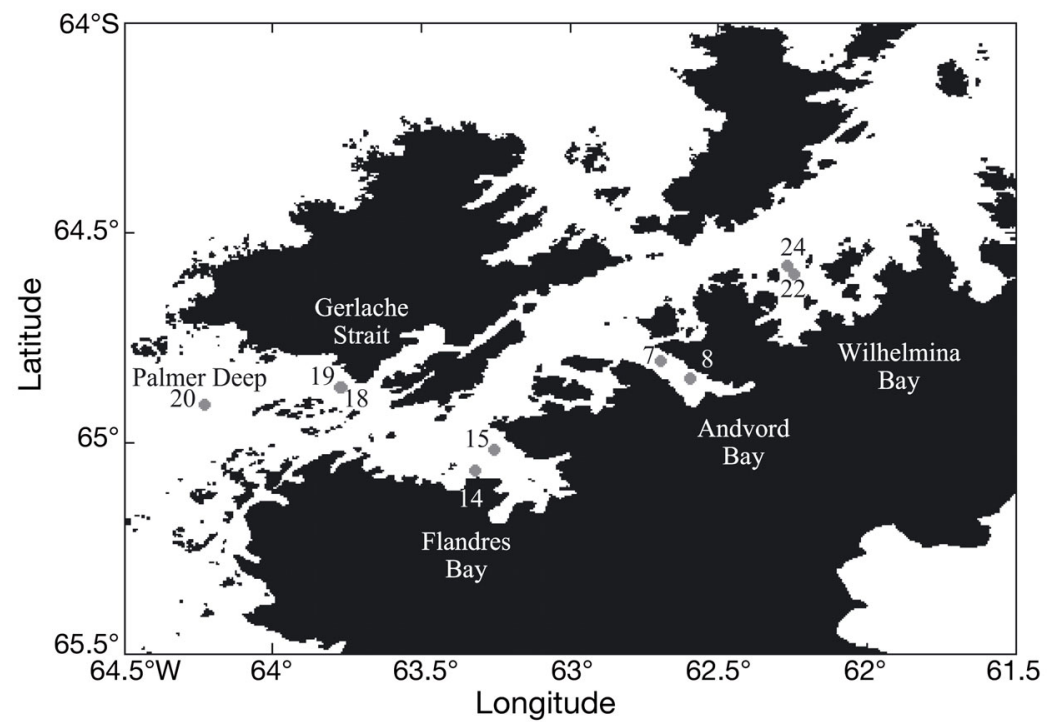

Fig. 1. MOCNESS tow locations. Tows 18 and 19 occurred at the same location at different times

Table 1. MOCNESS station information: dates are in 2013; time is local $24 \mathrm{~h}$ time (GMT $-4 \mathrm{~h})$

\begin{tabular}{|lllll|}
\hline $\begin{array}{l}\text { MOC } \\
\text { tow }\end{array}$ & Location & Latitude, longitude & Date & $\begin{array}{c}\text { Time } \\
\text { (local) }\end{array}$ \\
\hline 22 & Wilhelmina Bay & $64^{\circ} 36.01^{\prime} \mathrm{S}, 62^{\circ} 14.55^{\prime} \mathrm{W}$ & June 3 & $16: 18$ \\
24 & Wilhelmina Bay & $64^{\circ} 34.86^{\prime} \mathrm{S}, 62^{\circ} 15.93^{\prime} \mathrm{W}$ & June 4 & $11: 38$ \\
7 & Andvord Bay & $64^{\circ} 48.23^{\prime} \mathrm{S}, 62^{\circ} 41.56^{\prime} \mathrm{W}$ & May 23 & $22: 13$ \\
8 & Andvord Bay & $64^{\circ} 50.89^{\prime} \mathrm{S}, 62^{\circ} 35.82^{\prime} \mathrm{W}$ & May 24 & $09: 41$ \\
14 & Flandres Bay & $65^{\circ} 03.88^{\prime} \mathrm{S}, 63^{\circ} 19.11^{\prime} \mathrm{W}$ & May 29 & $21: 47$ \\
15 & Flandres Bay & $65^{\circ} 00.92^{\prime} \mathrm{S}, 63^{\circ} 15.28^{\prime} \mathrm{W}$ & May 30 & $09: 16$ \\
19 & Gerlache Strait & $64^{\circ} 51.94^{\prime} \mathrm{S}, 63^{\circ} 46.12^{\prime} \mathrm{W}$ & May 31 & $20: 35$ \\
18 & Gerlache Strait & $64^{\circ} 51.93^{\prime} \mathrm{S}, 63^{\circ} 46.30^{\prime} \mathrm{W}$ & May 31 & $11: 28$ \\
20 & Palmer Deep & $64^{\circ} 54.62^{\prime} \mathrm{S}, 64^{\circ} 13.78^{\prime} \mathrm{W}$ & June 1 & $05: 46$ \\
\hline
\end{tabular}

Vertically stratified samples of krill were collected with a $1 \mathrm{~m}^{2}$ MOCNESS equipped with nine $333 \mu \mathrm{m}$ mesh black nets. Two LED strobe lights (Brightwaters Instruments) were attached to the frame above the net mouth, and flashed continuously throughout all tows at approximately 2 flashes per second with a nominal light output of $3 \mathrm{~W}$, in order to reduce net avoidance behavior by krill (Sameoto et al. 1993, Wiebe et al. 2004, Lawson et al. 2004). However, despite the presence of bright strobes, black nets, and no bridle or other obstructions in front of the net opening, some krill individuals may still successfully avoid capture, and thus these net catch densities must be considered as a minimum estimate of the true krill abundance in the environment. The net was towed obliquely at a $45^{\circ}$ angle at 1.5 to 2 knots from $50 \mathrm{~m}$ above the seafloor to the surface. Net opening and closing depths varied between tows and were determined based on real-time information on the vertical distribution of krill from the Acoustic Doppler Current Profiler (ADCP) data in order to maximize vertical resolution of aggregation structure. Such acoustic guided net interval sampling allowed for separate samples above, within, and below krill aggregations, and pro-

CTD profiles were collecting using an SBE 911+ (SeaBird) CTD unit with dual salinity and temperature sensors, an in situ fluorescence unit, and a carousel of $22 \times 12-1$ Niskin bottles. Chlorophyll was measured from Niskin collected water at $5 \mathrm{~m}$ depth with extracted pigments in triplicate on a TD-700 fluorometer (Turner Designs) (Jespersen \& Christoffersen 1987).

Mesozooplankton were sampled with a $64 \mu \mathrm{m}$ mesh $0.5 \mathrm{~m}$ diameter ring net towed vertically at $15 \mathrm{~m} \mathrm{~min}^{-1}$ from $200 \mathrm{~m}$ to the surface. This fine-mesh net was used to sample the previously seldom sampled smaller zooplankton, including copepod nauplii. Cod end contents were preserved in $4 \%$ final concentration solution of sodium borate-buffered formalin in seawater. No clogging was evident because of the very low phytoplankton concentrations and volume filtered was calculated from the net mouth open area and depth of the tow. vides more accurate information about in situ density than fixed depth intervals that may sample both aggregation and empty water within a single net. Each net filtered between 53 and $900 \mathrm{~m}^{3}$ of water, with larger volumes necessary in depth intervals and locations where krill were less abundant.

Net catches were processed immediately. Catches were split on board the ship using a bucket splitter (a 201 cylinder with a $5 \mathrm{~cm}$ diameter tube extending from the bottom to a T-junction with identical $5 \mathrm{~cm}$ outflow tubes pouring into 2 separate 201 cylinders), as many times as required to produce a sample of roughly 150 to $200 \mathrm{ml}$ biovolume. Split samples were preserved in a $4 \%$ final concentration solution of sodium borate buffered formalin in seawater.

The ship-mounted ADCP, a narrow band $153 \mathrm{kHz}$ system mounted in a seawater-filled acoustic window, was configured for both current and volume 
backscattering measurements. Both the pulse and bin lengths were set at $8 \mathrm{~m}$, and the blank-aftertransmission was set to $4 \mathrm{~m}$. Volume backscattering measurements were acquired at approximately $1 \mathrm{~Hz}$ throughout the entire cruise. Because of technical difficulties in calibrating a ship-mounted $\mathrm{ADCP}$, the absolute estimates of biomass from backscattering measurements were reached empirically by comparison with estimates from other calibrated methods (Flagg \& Smith 1989, Zhou et al. 1994, Brierley et al. 1998, Nowacek et al. 2011). During ADCP data processing, corrections for absorption and range were made based on the standard sonar equation (Flagg \& Smith 1989, Zhou et al. 1994). Automatic Gain Control $\left(K_{c}\right)$ in the ADCP sonar equation was corrected using the equation developed from least squares fitting, minimizing the difference between a calibrated SIMRAD EK-60 and ADCP biomass estimates (Nowacek et al. 2011, Espinasse et al. 2012). Power into water $\left(K_{2}\right)$ was based on the manufacturer's value. To convert volume backscattering measurements to biomass, krill target strengths were estimated based on the mean and standard deviation of krill length analyzed from MOCNESS samples, literature values on the orientation and material properties of krill, and the deformed cylinder model (Chu et al. 1993, Chu \& Wiebe 2004, Lawson et al. 2006). ADCP backscattering data in $\mathrm{dB}$ were converted to biomass wet weight (WW) concentrations of krill in $\mathrm{g} \mathrm{m}^{-3}$ using a prolate spheroid model and the density of an individual krill approximately $1 \mathrm{~g}$ WW $\mathrm{cm}^{-3}$. Because the real $\mathrm{K}_{2}$ and $\mathrm{K}_{\mathrm{c}}$ are unknown, the measurements of backscattering and estimates of krill biomass should be treated as a relative metric, which can be used for analysing spatial variability rather than being an absolute measure of krill biomass.

\section{Laboratory processing}

In the laboratory, subsamples of $64 \mu \mathrm{m}$ net catches were taken with a 5 or $10 \mathrm{ml}$ Stempel pipet, for a target sample size of 200 individuals and all zooplankters, including any early life stage euphausiids, were identified and enumerated. Krill fecal pellet length and diameter were measured from photographs of Stempel samples in ImageJ (Schneider et al. 2012).

MOCNESS catches were further split if necessary in the lab for a final target sample size of $100 \mathrm{Eu}$ phausia superba individuals using a box splitter. The final counted sample ranged from the full net catch to a $128^{\text {th }}$ split. All krill which could be visually identified without magnification were counted from these splits, setting an operational lower size limit of $5 \mathrm{~mm}$ Standard Length, thus including adult and furcillia stages. Krill of $>5 \mathrm{~mm}$ in length will be quantitatively retained by the $333 \mu \mathrm{m}$ MOCNESS mesh (maximum mesh opening along diagonal $=471 \mu \mathrm{m}_{\text {; }}$ minimum diameter of a $5 \mathrm{~mm}$ long krill, given a 1:8 aspect ratio $=625 \mu \mathrm{m}$; Zhou \& Dorland 2004). For each krill individual, Standard 1 Length (anterior tip of telson to posterior end of uropods) was measured to the nearest $0.5 \mathrm{~mm}$ (as per Everson 2000), and individual krill were dried at $60^{\circ} \mathrm{C}$ for $\geq 24 \mathrm{~h}$ and weighed on a BP310S microbalance (Sartorius).

\section{Data processing}

Krill fecal pellet volume was calculated assuming a cylindrical shape and carbon estimated from the volume measurements using a factor of $0.058 \mathrm{mg} \mathrm{C}$ $\mathrm{mm}^{-3}$ (Gonzalez 1994, as cited in Dubischar \& Bathmann 2002), and an $80 \%$ carbon assimilation efficiency, a mid-range estimate from a rather wide range reported in the literature (Atkinson et al. $2012 \mathrm{~b}$ ). With fecal pellet sinking rates of around $300 \mathrm{~m} \mathrm{~d}^{-1}$ (Atkinson et al. 2012a) and the strong diel vertical migration observed, these fecal pellets most likely represent krill feeding over somewhere between 12 and $24 \mathrm{~h}$. To calculate the feeding rate necessary to produce the observed fecal pellets, highest and lowest fjord krill abundances were combined with lowest and highest fjord fecal pellet concentrations, respectively, to determine a range of feeding rates.

MOCNESS net catch data were used to calculate numbers and biomass of krill in each 2.5 and $5 \mathrm{~mm}$ length increment size fraction per $\mathrm{m}^{3}$ of water filtered in each depth interval and per $\mathrm{m}^{2}$ of integrated water column. Water column biomass estimate calculations used the conservative approach of assuming no krill were present in the unsampled, deepest part of the water column. Length-weight analysis was conducted as quality control on the data with MatLab's curve-fitting toolbox, and extreme outliers $(n=4)$ were removed as potentially erroneous. Differences in the length frequency distributions between tows were investigated by analyzing individual length data from each tow. Because some tows exhibited multiple peaks and were thus not normally distributed, we used both parametric and non-parametric ANOVA (Kruskal-Wallis) tests, followed by pairwise Tukey test comparisons between tows. 


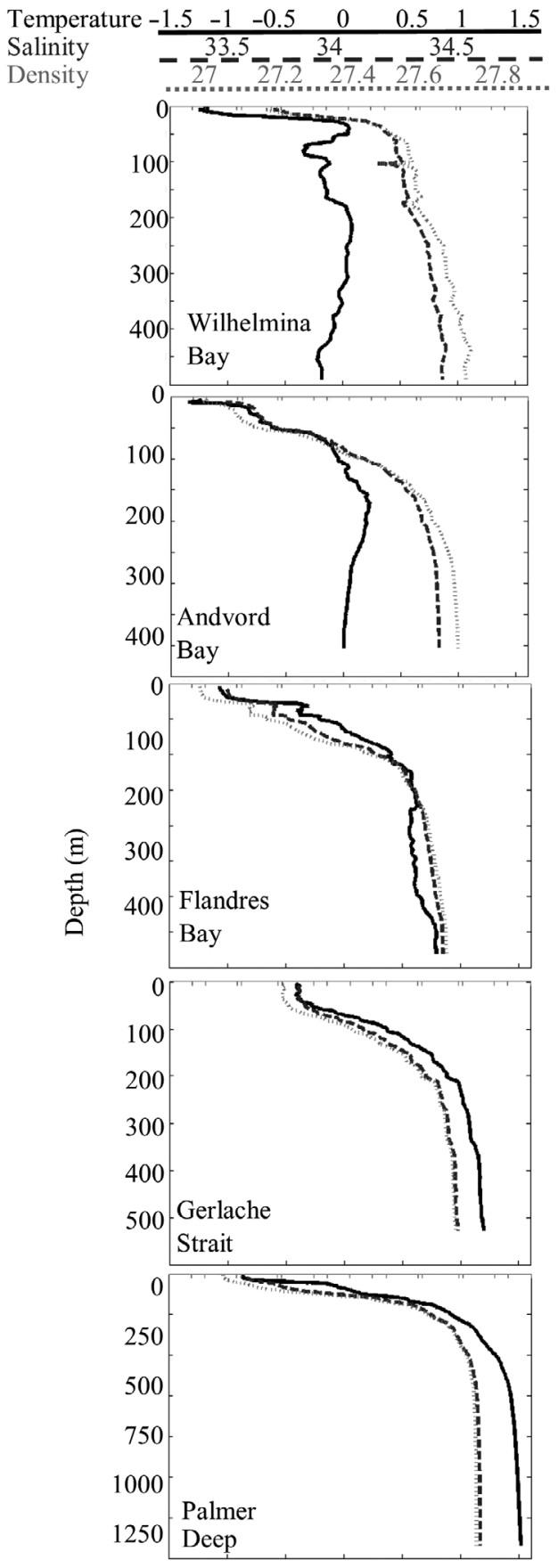

Fig. 2. CTD profiles of the areas sampled for krill. Temp: temperature $\left({ }^{\circ} \mathrm{C}\right)$, Salinity is in $\mathrm{psu}_{\text {; }}$ density is sigma-t in $\mathrm{kg} \mathrm{m}^{-3}$

ADCP backscatter data were observed qualitatively in real-time at sea, and were further examined in the laboratory by qualitatively examining profiles of 2-4 h blocks of time throughout the cruise. Broadscale spatial patterns were observed from watercolumn integrated acoustic backscatter. Binned and processed ADCP data $(8 \mathrm{~m}$ depth bins from 32 to $400 \mathrm{~m}$ depth, and 6 min time bins) were used for quantitative analyses. ADCP backscatter was analyzed to investigate patterns in the depth of krill aggregations. For each time interval the depth of maximum biomass was found in the ADCP record. These calculations excluded the $4 \mathrm{~m}$ immediately above the seafloor, as determined by Knudsen echosounder, due to potential noise from side-lobes of the ADCP beams, and excluded any time interval in which the maximum biomass did not exceed $50 \mathrm{~g}$ $\mathrm{m}^{-3}$, as such time intervals may indicate areas without krill or bad data due to bow-thruster noise. An ANOVA was used to investigate spatial differences in peak biomass density and diel variations in the depth of the biomass peak.

\section{RESULTS}

\section{Hydrography and chlorophyll}

The surface mixed layer ranged from 5 to $50 \mathrm{~m}$ in depth, with temperatures in the mixed layer ranging from $-1.7^{\circ} \mathrm{C}$ to $+0.5^{\circ} \mathrm{C}$ over the course of sampling, and mixed layer salinities between 33.4 and 34.4 psu (Fig. 2). Mixed layer water column properties were consistent with Antarctic Surface Water, while below the pycnocline warmer and saltier waters were observed, consistent with modified Circumpolar Deep Water (Lawson et al. 2004). This layer of Antarctic surface water was much more distinct within fjords than offshore, where pycnoclines were less sharp in the Gerlache and Palmer Deep Stations. Mixed layer chlorophyll was uniformly low throughout the study, with all values below $0.4 \mu \mathrm{g} \mathrm{l}^{-1}$ as determined from fluorometric measurements of extracted pigments (Table 2), and no clear chlorophyll maxima were observed from in situ fluorescence measurements.

Table 2. Water column chlorophyll a (mean \pm SD) from the different sampling locations $(\mathrm{n}=$ number of stations per location) for cruise NBP1304. Four depths were sampled at each station, with all samples in triplicate

\begin{tabular}{|lcc|}
\hline Location & $\mathrm{n}$ & $\mathrm{Chl} \mathrm{a}\left(\mu \mathrm{g} \mathrm{l}^{-1}\right)$ \\
\hline Wilhelmina & 2 & $0.33 \pm 0.02$ \\
Andvord & 4 & $0.33 \pm 0.02$ \\
Flandres & 3 & $0.24 \pm 0.01$ \\
Gerlache & 6 & $0.27 \pm 0.02$ \\
Palmer Deep & 1 & $0.20 \pm 0.04$ \\
\hline
\end{tabular}




\section{Mesozooplankton}

Almost no larger copepods were captured with the MOCNESS net. No early life stages of euphausiids were observed in the ring net samples. Zooplankton abundance is shown from the vertical net tows with $64 \mu \mathrm{m}$ ring net: abundances in the bays were very low, with between 45 and 226 ind. $\mathrm{m}^{-3}$ (Table 3), while in Gerlache Strait abundances were higher (1122 ind $\mathrm{m}^{-3}$ ). The sample from Palmer Deep was lost. Zooplankton samples were dominated by the small cyclopoid Oithona and the poecilostomatoid Oncaea. Other copepods present, but at very low abundances $\left(<4\right.$ ind. $\left.\mathrm{m}^{-3}\right)$, included Microcalanus pygmaeus, Scolocithricella, Metridia and Euchaeta, and unidentified calanoid and cyclopoid nauplii. Metridia were predominantly $M$. gerlachii, but also included the smaller M. lucens, as confirmed by $18 \mathrm{~S}$ rDNA sequencing (methods as per Durbin \& Casas 2014). At the Gerlache Strait stations the same taxa were observed but in abundances higher than those observed within the bays (Table 3).

Table 3. Zooplankton abundance (no. $\mathrm{m}^{-3}$, mean $\pm \mathrm{SD}$ ) for sampling locations during cruise NBP1304. Samples were collected with vertical hauls of a $0.064 \mu \mathrm{m}$ mesh $0.5 \mathrm{~m}$ diameter net. In Wilhelmina Bay and Flandres Bay 7 and 4 samples were collected, respectively, while Andvord Bay and Gerlache Strait results represent a single tow each. C1-C5, C6F/M: Copepodite stages 1-5, copepod adult stage 6 female/male, respectively

\begin{tabular}{|lcccc|}
\hline Zooplankter & Wilhelmina & Andvord & Flandres & Gerlache \\
\hline Ctenocalanus citer, C1-C5 & $0.29 \pm 0.58$ & 0.00 & $0.45 \pm 0.60$ & 0.00 \\
Euchaeta sp., C1-C5 & $0.15 \pm 0.38$ & 0.00 & $0.16 \pm 0.19$ & 0.00 \\
Metridia spp., nauplii & $0.07 \pm 0.19$ & 0.00 & $2.96 \pm 1.58$ & 57.30 \\
Metridia spp., C1-C5 & $0.87 \pm 1.16$ & 0.00 & $2.10 \pm 1.63$ & 6.37 \\
Metridia spp., C6F & $0.00 \pm 0.00$ & 0.00 & $0.51 \pm 0.30$ & 0.00 \\
Microcalanus pygmaeus, C1-C5 & $0.55 \pm 0.78$ & 2.04 & $4.01 \pm 1.11$ & 12.73 \\
Microcalanus pygmaeus, C6F & $0.07 \pm 0.19$ & 0.00 & $1.05 \pm 1.07$ & 0.00 \\
Microcalanus pygmaeus, C6M & $0.00 \pm 0.00$ & 0.00 & $0.00 \pm 0.00$ & 1.27 \\
Scolecithricella sp., C1-C5 & $2.29 \pm 2.68$ & 0.00 & $3.60 \pm 2.35$ & 15.28 \\
Scolecithricella sp., C6F & $0.25 \pm 0.39$ & 0.00 & $0.64 \pm 0.76$ & 0.00 \\
Scolecithricella sp., C6M & $0.00 \pm 0.00$ & 0.00 & $0.06 \pm 0.13$ & 0.00 \\
Calanoid spp., nauplii & $2.51 \pm 4.05$ & 0.51 & $12.16 \pm 7.27$ & 324.68 \\
Calanoid spp., C1-C5 & $0.04 \pm 0.10$ & 0.00 & $4.90 \pm 2.57$ & 39.47 \\
Oncaea sp., C1-C5 & $33.88 \pm 19.78$ & 19.35 & $34.63 \pm 10.1$ & 229.18 \\
Oncaea sp., C6F & $4.15 \pm 3.70$ & 0.51 & $15.53 \pm 4.61$ & 1.27 \\
Oncaea sp., C6M & $17.21 \pm 24.84$ & 1.02 & $19.03 \pm 8.59$ & 8.91 \\
Oithona sp., C1-C5 & $32.91 \pm 19.78$ & 21.90 & $84.57 \pm 35.2$ & 351.41 \\
Oithona sp., C6F & $5.34 \pm 1.94$ & 2.04 & $6.11 \pm 2.54$ & 3.82 \\
Oithona sp., C6M & $0.04 \pm 0.10$ & 0.00 & $0.06 \pm 0.13$ & 0.00 \\
Cyclopoid spp., nauplii & $11.59 \pm 12.38$ & 5.09 & $33.65 \pm 18.4$ & 71.30 \\
Harpacticoid copepod spp. & $0.47 \pm 0.43$ & 0.00 & $0.73 \pm 0.92$ & 0.00 \\
Total & $112.68 \pm 45.18$ & 52.46 & $226.54 \pm 66.8$ & 1122.99 \\
& & & & \\
\hline
\end{tabular}

\section{Krill fecal pellets}

Krill fecal pellets were observed in all of the bay samples, but not in Gerlache Strait. Estimated fecal pellet carbon was $27.5,81$, and $29.7 \mathrm{mg} \mathrm{C} \mathrm{m}^{-2}$, in Wilhelmina, Andvord and Flandres Bays, respectively. Thus the observed fecal pellets correspond to an estimated consumption rate of $0.035-1.21 \%$ of the krill biomass approximately daily.

\section{Krill from net sampling}

In total, 4047 krill were counted and measured from 56 discrete depth interval nets in 9 tows encompassing 3 bays and the more off-shore Gerlache Strait and Palmer Deep regions. Krill collected in MOCNESS tows were almost exclusively E. superba, with less than 5 individuals of Euphausia crystallorophias and Thysanoessa macrura encountered over the entire cruise. These other species of krill were not included in any analysis, and 'krill' is used throughout the remaining results and discussion to mean exclusively E. superba. Krill ranged in length from 9 to $51 \mathrm{~mm}$ and in dry weight from 0.001 to $0.217 \mathrm{~g}$.

The distribution of krill lengths showed a strong peak at sizes of 27.5 to $32.5 \mathrm{~mm}$, with a smaller secondary peak at 12.5 to $15 \mathrm{~mm}$ (Fig. 3). Krill from the larger size peak were found mainly within the bays, but were present in all tows, while the smallest size classes, representing young-ofthe-year (YOY) individuals, were mainly observed in the Gerlache Strait and Palmer Deep stations (Fig. 3). Not only did these more off-shore Gerlache and Palmer Deep tows have the highest relative abundances of krill in the smallest size fractions, they also had the highest total abundances of krill less than $20 \mathrm{~mm}$ in length (Fig. 3). Mean krill lengths were significantly different $(p<0.01)$ between all of the in-shore tows and the Palmer Deep and Gerlache Strait Day tows and these differences were robust to the choice of statistic (ANOVA/ 

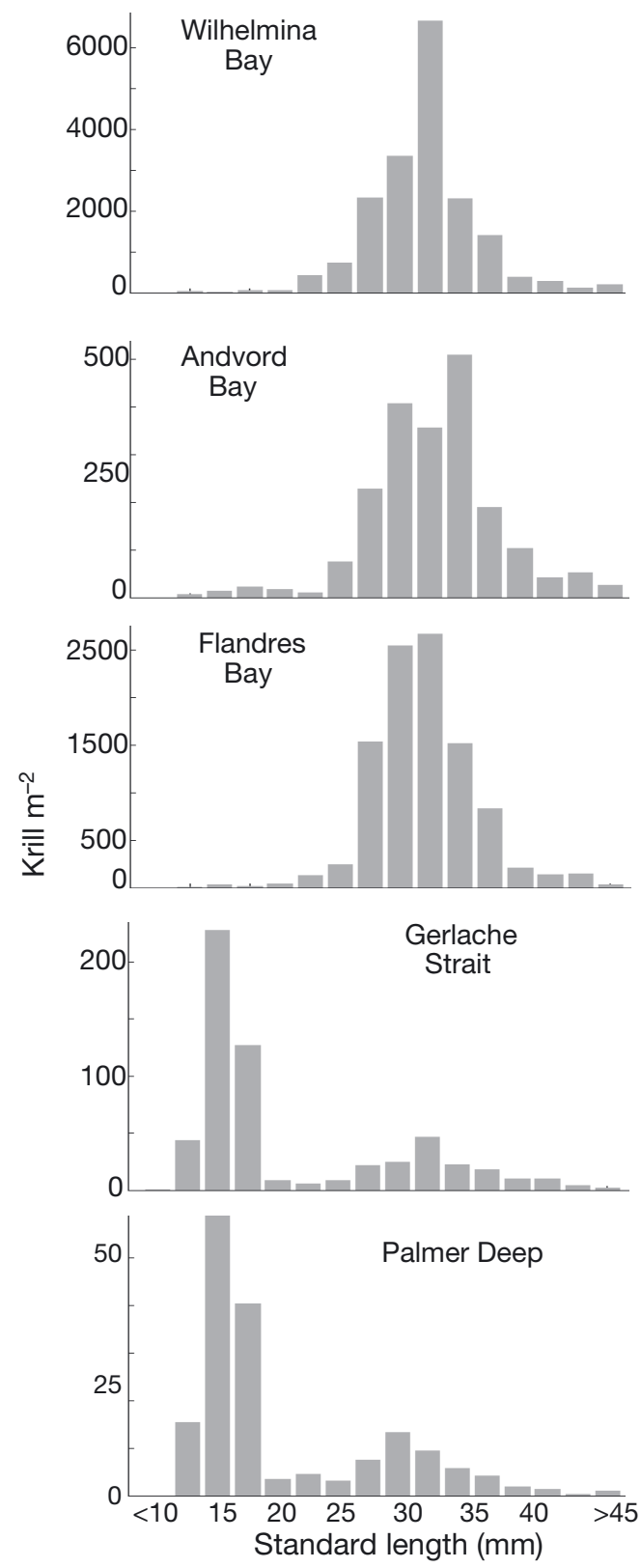

Fig. 3. Length-frequency histograms by location, showing the similar distributions observed in the 3 bays and the high contribution of young-of-the-year in the more off-shore Gerlache Strait and Palmer Deep samplings

Kruskal-Wallis). Palmer Deep and Gerlache Strait Day were significantly different from each other with ANOVA, but not with Kruskal-Wallis. The one other off-shore tow, Gerlache Strait Night (tow 18) was significantly different from all in-shore stations under ANOVA, but not significantly different from Andvord Bay night (tow 7) under Kruskal-Wallis (while still significantly different from all other bay tows). Within the bay stations, no clear patterns were observed in length distributions, with most tows not significantly different from each other under either analysis.

Krill abundances were much higher in the in-shore stations than in the Gerlache and Palmer Deep stations (Fig. 4, Table 4). Highest krill biomass was observed in Wilhelmina and Flandres Bays at night, with 506 and $308 \mathrm{~g} \mathrm{DW} \mathrm{m}^{-2}$, respectively. Lowest abundances and biomass were observed at Palmer Deep and the Gerlache Strait at night.

Vertical patterns of krill abundance showed both diel and spatial differences (Fig. 5). Within Wilhelmina, Andvord, and Flandres Bays a diel pattern was observed with krill more concentrated and deeper during the day, and relatively more dispersed and shallower at night (Fig. 5, Table 4). In the Gerlache Strait krill were concentrated in the upper $200 \mathrm{~m}$ of the water column during both day and night. No data are presented for Palmer Deep depth intervals 100150 or $500-700 \mathrm{~m}$ as the cod-ends were lost at sea.

\section{Acoustic sampling of krill}

General observations from the acoustic data were similar to patterns observed in MOCNESS tow catches. Although acoustic data are not able to sample the uppermost $(<24 \mathrm{~m})$ or lowermost $(>424 \mathrm{~m})$ parts of the water column, MOCNESS catches indicated that the shallowest depths contained relatively few krill individuals, and where seafloor depths exceeded ADCP sampling depths few krill were caught in these deepest layers, suggesting acoustic observations sampled the majority of the krill bio-

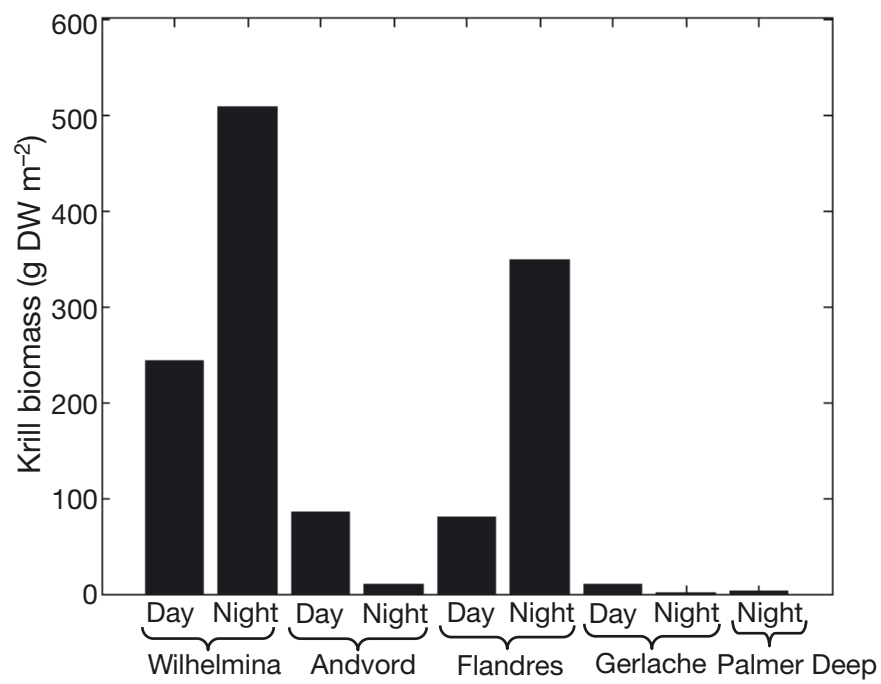

Fig. 4. Water column krill biomass (dry weight) in each tow 
Table 4. Krill length and weight (mean \pm SD), for each tow, number of krill analyzed and overall abundance for each tow. Total DW: water column total dry weight biomass of krill; weighted mean depth: index of the depth at which krill were located, calculated as the sum over all nets in a tow of $\left[\left(\right.\right.$ net $\left.\mathrm{krill} \mathrm{m}^{-2}\right) /\left(\right.$ water column $\left.\left.\mathrm{krill} \mathrm{m}^{-2}\right)\right] \times($ mean depth of net)

\begin{tabular}{|c|c|c|c|c|c|}
\hline Tow & $\begin{array}{l}\text { No. of krill } \\
\text { analysed }\end{array}$ & $\begin{array}{l}\text { Length } \\
\text { (mm) }\end{array}$ & $\begin{array}{l}\text { DW } \\
(g)\end{array}$ & $\begin{array}{l}\text { Total DW } \\
\left(\mathrm{g} \mathrm{m}^{-2}\right)\end{array}$ & $\begin{array}{c}\text { Weighted mean } \\
\text { depth }(\mathrm{m})\end{array}$ \\
\hline \multicolumn{6}{|c|}{ Wilhelmina } \\
\hline Night & 513 & $30.24 \pm 0.439$ & $0.039 \pm 0.019$ & 506.843 & 182 \\
\hline Day & 491 & $28.33 \pm 0.606$ & $0.035 \pm 0.02$ & 242.128 & 293.5 \\
\hline \multicolumn{6}{|c|}{ Andvord } \\
\hline Night & 265 & $26.37 \pm 1.012$ & $0.037 \pm 0.035$ & 10.399 & 100.3 \\
\hline Day & 286 & $30.82 \pm 0.705$ & $0.045 \pm 0.029$ & 84.558 & 231.7 \\
\hline \multicolumn{6}{|c|}{ Flandres } \\
\hline Night & 443 & $29.30 \pm 0.433$ & $0.038 \pm 0.02$ & 348.138 & 161.3 \\
\hline Day & 453 & $28.63 \pm 0.701$ & $0.036 \pm 0.023$ & 80.059 & 182.4 \\
\hline \multicolumn{6}{|c|}{ Gerlache } \\
\hline Night & 645 & $14.56 \pm 0.302$ & $0.006 \pm 0.008$ & 1.73 & 133.4 \\
\hline Day & 578 & $24.68 \pm 1.002$ & $0.034 \pm 0.033$ & 9.114 & 95.5 \\
\hline \multicolumn{6}{|c|}{ Palmer Deep } \\
\hline Night & 373 & $16.55 \pm 0.64$ & $0.010 \pm 0.014$ & 2.41 & 248.3 \\
\hline
\end{tabular}

mass throughout the cruise. No mesozooplankton were present in high enough abundances to have a significant impact on ADCP estimates of krill biomass, and we therefore consider all backscatter to have come from E. superba.

Krill abundance was higher within bays than in the Gerlache Strait and off-shore regions (Fig. 6). Peak krill abundance was statistically significantly differ- ent between each of the bays and the off-shore region ( $\mathrm{p}<0.01$ ), with abundances decreasing from Andvord to Wilhelmina, and then Flandres Bays, with lowest peak abundances in the Gerlache Strait and Palmer Deep off-shore region. During the day within bays, krill were typically concentrated in dense layers 50 to $100 \mathrm{~m}$ thick in the deepest part of the water column. Acoustically estimated biomass
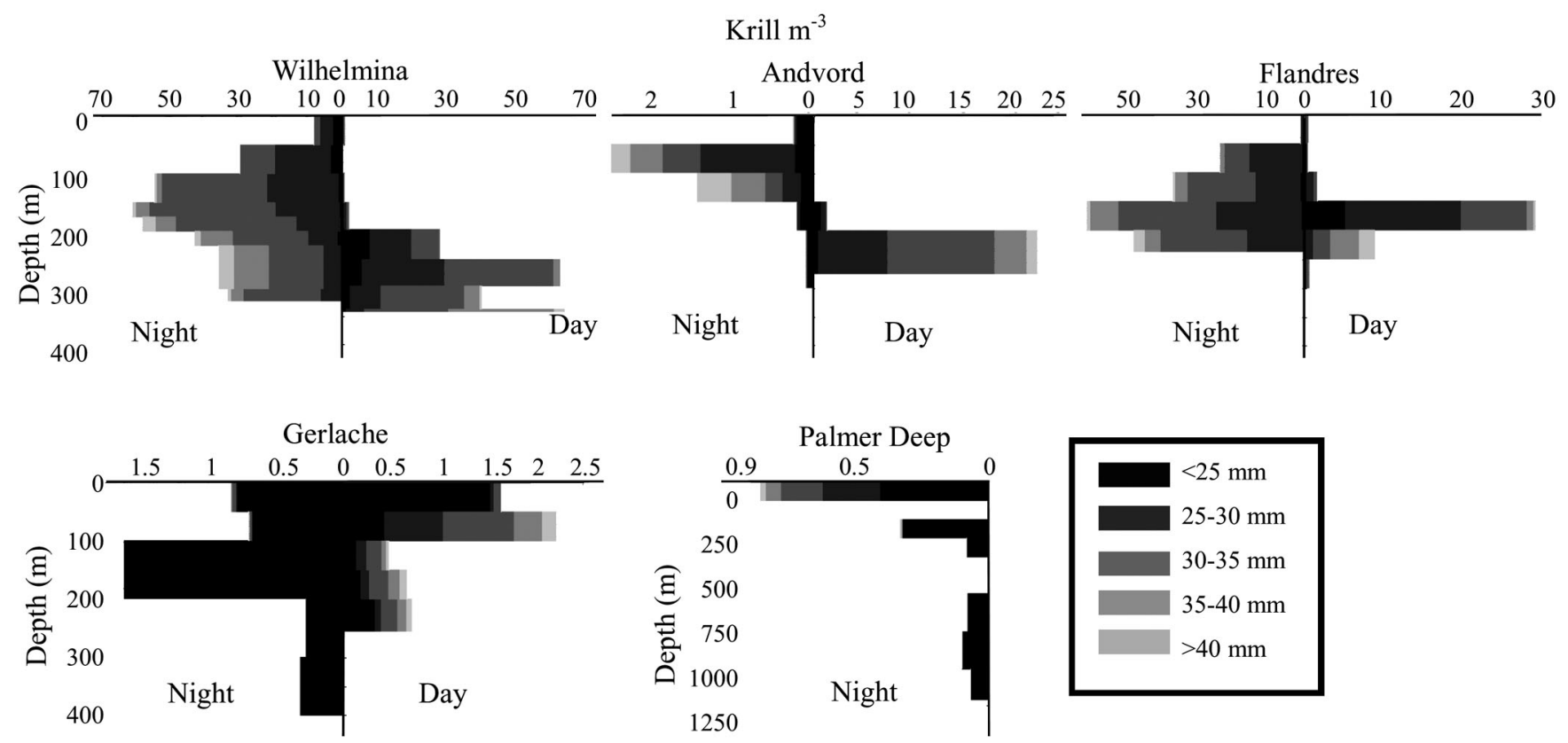

Fig. 5. Vertical profiles of size fractions of krill. Please note that the abundance scale is different in each plot to show details. Shade indicates the standard length of krill individuals, with the larger krill in the fjords (Wilhelmina, Andvord, Flandres), the small krill off-shore (Palmer Deep, Gerlache), and no consistent vertical partitioning by size 


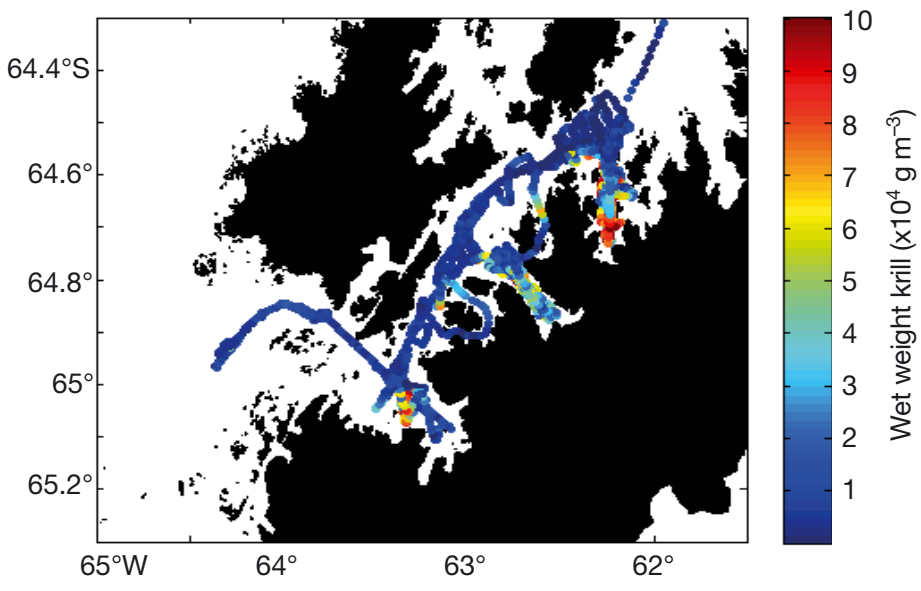

Fig. 6. Spatial distribution of krill in the West Antarctic Peninsula in winter (May-June) from acoustic estimates. Each point indicates the vertically integrated biomass from the surface to $400 \mathrm{~m}$ (or $10 \mathrm{~m}$ above the seafloor) in $\mathrm{g}$ wet weight $\mathrm{m}^{-3}$ averaged over a 6 min time interval

concentrations within these layers were at times in excess of $1000 \mathrm{~g} \mathrm{WW} \mathrm{m}^{-3}$. Where the seafloor was shallower than $300 \mathrm{~m}$, these aggregations were extended down to the sediment interface; where the seafloor was deeper, the aggregations tended to separate from the sediment but stay deep in the water column, typically between 200 and $300 \mathrm{~m}$. At night the krill tended to come up in the water column and form less dense aggregations. These night-time aggregations were typically most abundant between 100 and $200 \mathrm{~m}$ depth (Fig. 7) The depth of peak krill abundance was significantly different (ANOVA $\mathrm{p}<$ 0.001 ) between day, night, and twilight periods, with deepest mean peak depths in the day (10:00 to 14:00 h, $239.5 \mathrm{~m}$ ), shallowest mean peak depths at night (16:00 to $08: 00 \mathrm{~h}, 162.6 \mathrm{~m})$, and intermediate depths at twilight (08:00 to $10: 00 \mathrm{~h}$ and 14:00 to 16:00 h, $207.5 \mathrm{~m}$ ) (Fig. 7). Outside of the bays in the Gerlache Strait area acoustic krill biomass estimates were generally very low, with the few observations of higher biomass close to the coasts (Fig. 6).

\section{DISCUSSION}

Very high densities of Euphausia superba, in excess of 8000 individuals and $1700 \mathrm{~g} \mathrm{WW}$ biomass $\mathrm{m}^{-2}$, were observed in the coastal fjords of the WAP in winter. Previous work in these coastal embayments has also suggested their importance as winter habitat for krill (Zhou et al. 1994, Zhou \& Dorland 2004, Lawson et al. 2004, 2008, Friedlaender et al. 2013). As early as 1938 the importance of these areas as krill habitat were noted, with 'E. superba in millions a yard or two from the shore near Andvord Bay' (Bagshawe 1938, as cited in Marr 1962). In adjacent

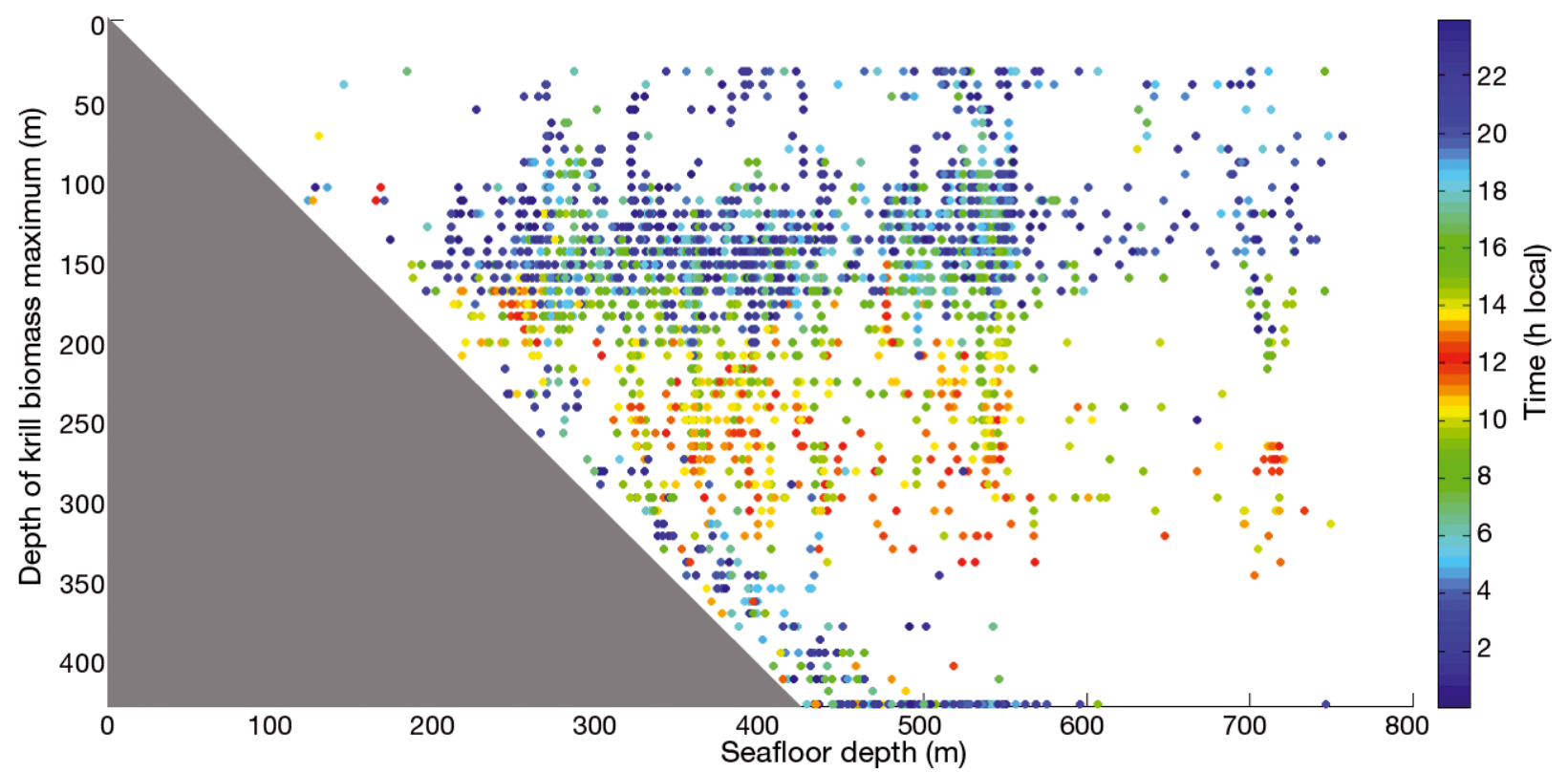

Fig. 7. Krill peak abundance depth over the range of bottom depths. Each point indicates the depth of maximum krill biomass, as compared to the seafloor depth, averaged over $6 \mathrm{~min}$, with color indicating local time of sampling (GMT - 4 h). Points are in order of bottom depth, regardless of order of sampling. Krill tended to either occur close to the seafloor (points along the triangle hypotenuse) or in a layer at 100-200 m depth (points in the horizontal layer). ADCP provides reliable data between 24 and $424 \mathrm{~m}$ depth; uppermost and lowermost areas of the water column are not quantitatively sampled 
more open water areas in the Gerlache Strait and Palmer Deep krill abundances were orders of magnitude lower (1-9 $\mathrm{g} \mathrm{WW} \mathrm{m}^{-2}$ ). This relative lack of krill in winter in the more commonly sampled Gerlache Strait and off-shore areas has also been previously observed, with shelf-wide density estimates of only $2 \mathrm{~g} \mathrm{WW} \mathrm{m}^{-2}$ (Siegel et al. 2013) and $8 \mathrm{~g} \mathrm{WW} \mathrm{m}^{-2}$ (Lascara et al. 1999). Our abundance estimates are based on 2 independent methods (nets and acoustics) indicating that the high values observed within fjords very likely show true areas of high krill concentrations.

If we consider the average values of the more offshore areas from our MOCNESS sampling (Palmer Deep and Gerlache Strait) to be representative of krill densities over the shelf as a whole, and the densities observed within the 3 sampled fjords (Wilhelmina, Andvord, and Flandres) to be representative of the fjordic bays along the WAP overall, we estimate that close to $90 \%$ of the total krill biomass in the WAP region may be present within fjords in winter. This is despite the shelf region being an order of magnitude larger in extent ( $200 \mathrm{~km}$ wide vs. $20 \mathrm{~km}$ wide) than the fjords, and containing well over an order of magnitude more potential habitat due to greater depth. This concentration of krill within WAP fjordic bays in winter is in stark contrast to summer and fall, when krill are abundant over the shelf, and are more typically concentrated into small schools with large areas of empty water between schools (Lascara et al. 1999, Lawson et al. 2008), while within fjords only small aggregations are observed (E. G. Durbin \& M. Zhou unpubl. data). In the remainder of the discussion we consider potential reasons and mechanisms for the observed high winter densities in fjords.

\section{Advection into fjords}

Krill are often modeled as passive drifters, and their presence in fjords and canyons may be driven by advection (Schofield et al. 2013, Bernard \& Steinberg 2013). Canyons can interrupt the along-shelf flow, serving as conduits for cross-shelf exchange (Allen \& Durrieu de Madron 2009). Such cross shelf flow can transport krill into canyons, and retain them in those areas (She \& Klinck 2000). High concentrations of euphausiids have been observed in canyons and shelf break regions globally (e.g. Gulf of St. Lawrence: Simmard et al. 1986, Sourisseau et al. 2006, 2008; Georges Bank: Greene et al. 1988, Jech \& Michaels 2006; Bering Sea: Coyle \& Cooney 1993;
WAP: Lawson et al. 2004). Along the WAP, concentrations of krill in canyons have been particularly noted at the head of Palmer Deep Canyon (Bernard \& Steinberg 2013), and at the head of the canyon north of Livingstone Island (Warren et al. 2009). This concentration of krill in canyons is not however universal, with low krill backscatter observed near Marguerite trench, as compared to the surrounding areas (Lawson et al. 2004, 2008).

While advection certainly plays a role in E. superba distributions, it does not appear that cross-shelf advection in fjordic canyons is the most plausible explanation for the high winter abundance observed within the WAP fjords. The along-shelf coastal current and the canyon bathymetry are present year round, yet krill are abundant in fjords only in winter. Additionally, the biomass of krill present in the fjords, and the very low abundances observed across the shelf, both in the present work and in more extensive surveys (Siegel 1988, Lascara et al. 1999), suggest krill from across the shelf are moving into fjords in winter, whereas advective flows in canyons would likely impact only those krill closest to the fjord mouths. Thus, an alternative factor must be at least partially responsible for the observed high winter densities within fjords.

\section{Active in-shore seasonal migration}

We suggest that rather than a purely physical aggregating mechanism, the most likely process leading to krill aggregation in fjords in winter is active migration as part of an overwintering strategy. Active migration has previously been suggested as a mechanism for the observed seasonal differences in krill spatial distributions, and modeling suggests active directed movements by krill significantly enhance their growth and reproductive sucess (Siegel 1988, 2005, Lawson et al. 2004, Richerson et al. 2015). These earlier studies suggesting such an active inshore migration did not sample the very near shore region studied here, and thus found lower overall abundances in winter as compared to other seasons (Marr 1962, Siegel 1988, 2005, Lawson et al. 2004). This new data showing very high densities and abundances of krill within the coastal fjords supports the concept of an active seasonal on-off shore migration, and helps to account for the previously missing krill in winter. Krill are sometimes classified as 'micronekton' rather than plankton because of their swimming abilities. On small spatial scales, krill swimming is important in maintaining desired loca- 
tions, likely associated with opportunities for feeding, reproduction or reduced predation risk (Mackas et al. 1997, Tarling et al. 1998, Zhou et al. 2005). Krill have also been observed to use their swimming abilities in large-scale movements. Krill have been observed swimming against a current and swarms use this ability to maintain positions even in the main flow of the Antarctic Circumpolar Current (Marr 1962, Tarling \& Thorpe 2014). In East Antarctica krill swarm movements have been tracked over multiple weeks, covering distances up to $185 \mathrm{~km}$ (Kanda et al. 1982). These aggregations migrated at speeds of 0.11 to $0.13 \mathrm{~m} \mathrm{~s}^{-1}$, at which speeds krill could move from the shelf edge to the inner area of a coastal fjord in 2 to $3 \mathrm{wk}$.

\section{Minimizing advective losses}

An active migration such as we hypothesize for krill in the WAP would require energy expenditure by the krill, and thus for such a strategy to have developed and become widespread in the population it must offer significant benefits to krill survival or reproduction. One potential benefit to krill of spending the winter within fjords is the minimization of advective losses from the favorable WAP region or minimization of energetic expenditures from counter-current swimming to maintain position. The WAP is a highly productive area, with high primary productivity fed by nutrient enrichment from circumpolar deep water (Ducklow et al. 2007). It would thus be beneficial for krill to stay within the WAP region. It remains unclear to what extent this is the case, with indications that krill within the WAP region are a self-sustaining population (Quetin \& Ross 2003), and models suggest that krill may complete their full life cycle there (Hofmann \& Husrevoglu 2003), but also that krill populations within the WAP area may be maintained by both local recruitment and advective input of larvae from other regions (Piñones et al. 2013).

The WAP area is a highly advective environment, with the Antarctic Circumpolar Current carrying water, and potentially krill, to the northeast and out of the area, while the coastal current could advect individuals away to the southwest (Nicol 2006). Entering bays, in which current flows are much lower than in the Bransfield Strait and broader shelf region, would prevent krill from being advected out of the area, or allow krill to reduce energy expenditures on swimming to maintain position. Reduced advection out of the WAP area, or energy savings from reduced maintenance swimming, may be particularly beneficial during the winter season with low food resources. In Marguerite Bay, in fall and winter, krill are most abundant where currents and current sheer are lowest (Lawson et al. 2008), which might suggest krill selecting retentive environments as habitat. In addition to the broadscale current flows, katabatic winds blowing down the glaciers and over the fjords may move surface waters offshore. Krill within fjords were observed not to be present within these surface layers of cold fresh water, while in the more offshore areas without such strong stratification and katabatic winds, they were present in even the shallowest layers. This is consistent with a strategy of minimizing advective losses.

Differences between individuals in swimming ability may also play a role in the different benefits of such minimization of advection to each krill. Krill swimming ability is a function of length with maximal sustained speeds around 8 body lengths $\mathrm{s}^{-1}$ (Kils 1981). As a result krill will segregate by size while migrating. Within fjords, krill length distributions showed a single peak, with slight indications of a higher secondary peak in Andvord Bay. This peak length corresponds to krill of age 1+, that is those hatched around January 2012. Smaller YOY krill were observed in the further off-shore samples, and larger krill corresponding to age 3 and greater were very rare in our sampling. It is possible that the smallest and youngest individuals are not able to make a seasonal migration all the way into the fjords (although other possibilities are discussed below). Larger krill may find maintaining position against a current to be less of a metabolic burden than age 1+ krill, and may choose to stay in an area with fewer predators than the coastal fjords. The observed abundance of age 1+ krill could also be related to multiyear patterns in krill recruitment, as 2013 was a particularly high recruitment year for krill in the WAP region (Steinberg et al. 2015), although the lack of a strong age 2+ year class within the fjords suggests recruitment variability is not the full explanation for the observed length distributions as 2012 was also a strong krill recruitment year (Steinberg et al. 2015).

\section{Near-shore food resources}

Fjords may also offer food resources not available to krill remaining further out on the shelf in winter. Algal prey, traditionally considered the most important food item for E. superba, are at very low levels in winter throughout the WAP region, due to very low 
light levels with both short day lengths (approximately $4 \mathrm{~h} \mathrm{~d}^{-1}$ ), and low sun angle. The very low abundance of water column algae can be seen in the very low chlorophyll values observed. Similarly, no ice algae were observed at the time of sampling as sea ice was just forming. However, it is clear from the fecal pellets observed within fjords that krill were feeding at least to some degree in these regions in winter. The importance of winter feeding may also vary as krill mature. E. superba accumulates storage lipids in summer and depletes these reserves in winter (Hagen et al. 2001). If larger age 2+ and older krill are able to accumulate more lipids, relative to their metabolic needs, than smaller krill, they may be less reliant on winter near-shore feeding and may choose to remain outside of our sampling region. Such larger krill have often been observed over the shelf region and more off-shore areas not sampled in our cruise, although it is again possible that variations in yearclass success are partially responsible for the observed patterns (Siegel 1987, Lascara et al. 1999).

Krill may rely on alternative, non-phytoplankton food sources, such as sediments and associated phytodetritus (Schmidt et al. 2011) or mesozooplankton (Nordhausen et al. 1992, Huntley et al. 1994, Atkinson \& Snÿder 1997) in the winter period of scarce phytoplankton. Cross-shelf advective flows, described earlier, may bring mesozooplankton into the fjords, enhancing opportunities for carnivorous feeding by krill. Within fjords, mesozooplankton abundances were roughly an order of magnitude lower than further out on the shelf, suggesting potential top-down effects of krill predation on mesozooplankton within the fjords. However, at the low abundances of mesozooplankton observed, it does not seem likely that this was the main food source sustaining the large krill population and leading to the observed fecal pellets. Similarly, YOY krill were at much lower abundances within fjords than they were off-shore, which may potentially reflect cannibalistic feeding by the larger age $1+$ krill which dominated the fjords. Cannibalism was observed in our onboard krill incubations (A. C. Cleary unpubl. data), and has been previously documented for E. superba (Ligowski 2000).

The most likely food resource for krill within the fjords is sediments and associated detritus. Krill have been suggested to feed on epibenthic diatoms in some regions (Ligowski 2000), or detritus settling out from the water column and preserved by the cold bottom waters as a kind of 'food bank' (Smith et al. 2006, Schmidt et al. 2011). Krill were observed to spend daylight hours in dense aggregations, with the deepest individuals right on the sediment interface. These observations were consistent between acoustics, underwater videography (NBP1304 cruise report), and near-bottom Niskin sampling of krill (E. G. Durbin unpubl. data). There is growing evidence of the importance of epibenthic habitat for $E$. superba. Dense near-bottom aggregations have been observed with ROVs near the shelf break in the Weddell Sea (Gutt \& Siegel 1994), and in the deep waters beyond the shelf break in the WAP region (Clarke \& Tyler 2008, Brierley 2008). In total over 14 studies have observed epibenthic E. superba, with observations covering much of their distributional range (Schmidt et al. 2011). Sediment food resources have been recognized as potentially seasonally important for E. superba in the WAP and other relatively shallow coastal regions (Schmidt et al. 2011).

Krill in our study formed dense aggregations near the seafloor during daylight hours, provided the seafloor was shallower than $300 \mathrm{~m}$. At the bottom of these aggregations krill were within a few meters of the seafloor, and were interacting with the sediment (camera observations; E. G. Durbin et al. unpubl. data). A large number of krill ( 160) were collected from one of these observed dense aggregations in Andvord Bay simply by closing a 121 Niskin bottle near the seafloor while within the aggregation. The guts of these near bottom krill were full of dark material, demonstrating that these krill were actively ingesting sediment. When starved krill individuals were placed in incubations with undisturbed sediment and overlaying waters they immediately swam to the sediment and began stirring up particles and actively filtering the stirred up particles with their thoracic limbs (M. Orchard pers. comm.), again suggesting sediments are a common and potentially important food resource for krill in this region in winter.

The relatively shallow depths of the sampled fjords may explain the value of sediment food resources. The availability of such sediment food resources has also been suggested to explain the more rapid maturation of krill in the WAP, as compared to other regions, such as the Lazarev Sea, where sediment food resources are less available to krill (Schmidt et al. 2014). Krill overwintering strategies are known to vary across their geographic range (Schmidt et al. 2014); for E. superba i

$\mathrm{n}$ the central WAP region at least, it appears that near-shore benthic feeding may be an important component of the overwintering strategy, and may serve as one of the drivers of seasonal in-shore migration by krill in this region. 


\section{CONCLUSIONS}

E. superba, particularly age 1+ individuals, were observed in very high densities within 3 coastal fjords along the WAP in winter. These aggregations, in combination with previously reported summer distributions, suggest an active, seasonal on-shore migration. Active migration of krill into fjords in winter may help reduce advective losses from the WAP region, or conserve energy spent maintaining position within the advective shelf region. Fjords may also offer important food resources to krill during this period of very low phytoplankton, particularly in the sediments. Highdensity krill aggregations at the sediment interface suggest epibenthic feeding may be important for E. superba in this region in winter, and potentially one of the drivers of onshore migrations. Improved understanding of the role of fjords and epibenthic areas as habitat for krill helps to refine our understanding of the complex ecology of this keystone species. The role of these previously often underrecognized krill habitats may be important to consider in spatial planning and managing the growing fishery for this species to protect geographically limited but potentially ecologically important krill winter habitat.

Acknowledgements. Many thanks to Iain McCoy and Michelle Dennis for assistance with sample collection at sea and to David Gleeson for laboratory assistance. Thanks to the technicians, command, and crew of NBP1304. This research was supported by National Science Foundation Office of Polar Programs grant \#ANT-1142107 to E.G.D and M.Z.

\section{LITERATURE CITED}

Allen SE, Durrieu de Madron X (2009) A review of the role of submarine canyons in deep-ocean exchange with the shelf. Ocean Sci 5:607-620

Atkinson A, Snÿder R (1997) Krill-copepod interactions at South Georgia, Antarctica, I. Omnivory by Euphausia superba. Mar Ecol Prog Ser 160:63-76

Atkinson A, Siegel V, Pakhomov EA, Rothery P and others (2008) Oceanic circumpolar habitats of Antarctic krill. Mar Ecol Prog Ser 362:1-23

> Atkinson A, Schmidt K, Fielding S, Kawaguchi S, Geissler PA (2012a) Variable food absorption by Antarctic krill: relationships between diet, egestion rate and the composition and sinking rates of their fecal pellets. Deep-Sea Res II 59-60:147-158

Atkinson A, Nicol S, Kawaguch S, Pakhomov E and others (2012b) Fitting Euphausia superba into Southern Ocean food-web models: a review of data sources and their limitations. CCAMLR Sci 19:219-245

> Bernard KS, Steinberg DK (2013) Krill biomass and aggregation structure in relation to tidal cycle in a penguin foraging region off the Western Antarctic Peninsula. ICES J Mar Sci 70:834-849

Brierley AS (2008) Antarctic ecosystems: Are deep krill ecological outliers or portents of a paradigm shift? Curr Biol 18:R252-R254

Brierley AS, Brandon MA, Watkins JL (1998) An assessment of the utility of an Acoustic Doppler Current Profiler for biomass estimation. Deep-Sea Res I 45:1555-1573

- Chu D, Wiebe PH (2005) Measurements of sound-speed and density contrasts of zooplankton in Antarctic waters. ICES J Mar Sci 62:818-831

> Chu D, Foote KG, Stanton TK (1993) Further analysis of target strength measurements of Antarctic krill at 38 and $120 \mathrm{kHz}$ : Comparison with deformed cylinder model and inference of orientation distribution. J Acoust Soc Am 93: 2985-2988

Clarke A, Tyler PA (2008) Adult Antarctic krill feeding at abyssal depths. Curr Biol 18:282-285

Coyle KO, Cooney RT (1993) Water column sound scattering and hydrography around the Pribilof Islands, Bering Sea. Cont Shelf Res 13:803-827

> Dubischar CD, Bathmann UV (2002) The occurrence of faecal material in relation to different pelagic systems in the Southern Ocean and its importance for vertical flux. Deep-Sea Res II 49:3229-3242

Ducklow HW, Baker K, Martinson DG, Quetin LB, Ross RM, Smith RC, Fraser W (2007) Marine pelagic ecosystems: the west Antarctic Peninsula. Phil Trans R Soc Lond B 362:67-94

Durbin EG, Casas MC (2014) Early reproduction by Calanus glacialis in the Northern Bering Sea: the role of ice algae as revealed by molecular analysis. J Plankton Res 36: 523-541

Espinasse B, Zhou M, Zhu Y, Hazen EL and others (2012) Austral fall-winter transition of mesozooplankton assemblages and krill aggregations in an embayment west of the Antarctic Peninsula. Mar Ecol Prog Ser 452:63-80

Everson I (2000) Biological observations In: Everson I (ed) Krill biology, ecology, and fisheries. Blackwell Science, Oxford, p 33-39

- Flagg CN, Smith S (1989) Zooplankton abundance measurements from acoustic Doppler current profilers. OCEANS'89 Proceedings 5:1318-1323

Friedlaender AS, Tyson RB, Stimpert AK, Read AJ, Nowacek DP (2013) Extreme diel variation in the feeding behaviour of humpback whales along the western Antarctic Peninsula during autumn. Mar Ecol Prog Ser 494:281-289

Greene CH, Wiebe PH, Burczynski J, Youngbluth MJ (1988) Acoustical detection of high-density krill demersal layers in the submarine canyons off Georges Bank. Science 241:359-361

Gutt J, Siegel V (1994) Benthopelagic aggregations of krill (Euphausia superba) on the deeper shelf of the Weddell Sea (Antarctic). Deep-Sea Res I 41:169-178

> Hagen W, Kattner G, Terbrüggen A, Van Vleet ES (2001) Lipid metabolism of the Antarctic krill Euphausia superba and its ecological implications. Mar Biol 139: 95-104

Hamner WM (1984) Aspects of schooling in Euphausia superba. J Crustac Biol 4:67-74

Hamner WM, Hamner PP (2000) Behavior of Antarctic krill (Euphausia superba): schooling, foraging, and antipredatory behaviour. Can J Fish Aquat Sci 57:192-202

Hofmann EE, Husrevoglu YS (2003) A circumpolar model- 
ing study of habitat control of Antarctic krill (Euphausia superba) reproductive success. Deep-Sea Res II 50: 3121-3142

- Huntley ME, Nordhausen W, Lopez MDG (1994) Elemental composition, metabolic activity and growth of Antarctic krill Euphausia superba during winter. Mar Ecol Prog Ser 107:23-40

> Jech JM, Michaels WL (2006) A multifrequency method to classify and evaluate fisheries acoustics data. Can J Fish Aquat Sci 63:2225-2235

Jespersen AM, Christoffersen K (1987) Measurements of chlorophyll-a from phytoplankton using ethanol as extractions solvent. Arch Hydrobiol 9:445-454

Johnston DW, Friedlaender AS, Read AJ, Nowacek DP (2012) Initial density estimates of humpback whales Megaptera novaeangliae in the inshore waters of the western Antarctic Peninsula during the late autumn. Endang Species Res 18:63-71

Kanda K, Takagi K, Seki Y (1982) Movement of the larger swarms of Antarctic krill Euphausia superba population off Enderby Land during 1976-1977 season. J Tokyo Univ Fisheries (Japan) 68:25-42

Kils U (1981) Swimming behaviour, swimming performance and energy balance of Antarctic krill, Euphausia superba. BIOMASS Scientific Series No. 3 SCAR

> Lascara CM, Hofmann EE, Ross RM, Quetin LB (1999) Seasonal variability in the distribution of Antarctic krill, Euphausia superba, west of the Antarctic Peninsula. Deep-Sea Res I 46:951-984

Lawson GL, Wiebe PH, Ashjian CJ, Gallager SM, Davis CS, Warren JD (2004) Acoustically-inferred zooplankton distribution in relation to hydrography west of the Antarctic Peninsula. Deep-Sea Res II 51:2041-2072

Lawson GL, Wiebe PH, Ashjian CJ, Chu D, Stanton TK (2006) Improved parametrization of Antarctic krill target strength models. J Acoust Soc Am 119:232-242

Lawson GL, Wiebe PH, Ashjian CJ, Stanton TK (2008) Euphausiid distribution along the Western Antarctic Peninsula - Part B: Distribution of euphausiid aggregations and biomass, and associations with environmental features. Deep-Sea Res II 55:432-454

Ligowski R (2000) Benthic feeding by krill, Euphausia superba Dana, in coastal waters off West Antarctica in Admiralty Bay, South Shetland Islands. Polar Biol 23: 619-625

> Mackas DL, Kieser R, Saunders M, Yelland DR, Brown RM, Moore DF (1997) Aggregation of euphausiids and Pacific hake (Merluccius productus) along the outer continental shelf off Vancouver Island. Can J Fish Aquat Sci 54: 2080-2096

Marr JWS (1962) The natural history and geography of the Antarctic krill (Euphasia superba Dana). Discov Rep 37. Cambridge University Press, Cambridge

Nicol S (2006) Krill, currents, and sea ice: Euphausia superba and its changing environment. Bioscience 56: $111-120$

Nordhausen W, Huntley M, Lopez M (1992) RACER: carnivory by Euphausia superba during the Antarctic winter. Antarct J US 27:181-182

> Nowacek DP, Friedlaender AS, Halpin PN, Hazen EL and others (2011) Super-aggregations of krill and humpback whales in Wilhelmina Bay, Antarctic Peninsula. PLoS ONE 6:e19173

Piñones A, Hofmann EE, Daly KL, Dinniman MS, Klinck JM (2013) Modeling the remote and local connectivity of
Antarctic krill populations along the western Antarctic Peninsula. Mar Ecol Prog Ser 481:69-92

> Quetin LB, Ross RM (1991) Behavioral and physiological characteristics of the Antarctic krill, Euphausia superba. Am Zool 31:49-63

Quetin LB, Ross RM (2003) Episodic recruitment in Antarctic krill Euphausia superba in the Palmer LTER study region. Mar Ecol Prog Ser 259:185-200

Richerson K, Watters GM, Santora JA, Schroeder ID, Mangel M (2015) More than passive drifters: a stochastic dynamic model for the movement of Antarctic krill. Mar Ecol Prog Ser 529:35-48

Sameoto D, Cochrane N, Herman A (1993) Convergence of acoustic, optical, and net-catch estimates of euphausiid abundance: use of artificial light to reduce net avoidance. Can J Fish Aquat Sci 50:334-346

> Schmidt K, Atkinson A, Steigenberger S, Fielding S and others (2011) Seabed foraging by Antarctic krill: implications for stock assessment, bentho-pelagic coupling, and the vertical transfer of iron. Limnol Oceanogr 56:1411-1428

> Schmidt K, Atkinson A, Pond DW, Ireland LC (2014) Feeding and overwintering of Antarctic krill across its major habitats: the role of sea ice cover, water depth, and phytoplankton abundance. Limnol Oceanogr 59:17-36

Schneider CA, Rasband WS, Eliceirir KW (2012) NIH Image to ImageJ: 25 years of image analysis. Nat Methods 9: 671-675

Schofield OM, Ducklow HW, Bernard K, Doney SC, Patterson-Fraser D, Gorman K, Fraser WR (2013) Penguin biogeography along the West Antarctic Peninsula: testing the canyon hypothesis with Palmer LTER observations. Oceanography 26:204-206

She J, Klinck JM (2000) Flow near submarine canyons driven by constant winds. J Geophys Res Oceans 105(C12):28671-28694

Siegel V (1987) Age and growth of Antarctic Euphausiacea (crustaecea) under natural conditions. Mar Biol 96: 483-495

Siegel V (1988) A concept of seasonal variation of krill (Euphausia superba) distribution and abundance west of the Antarctic Peninsula. In: Sahrhange D (ed) Antarctic ocean and resources variability. Springer-Verlag, Berlin, p 219-230

> Siegel V (2005) Distribution and population dynamics of Euphausia superba: summary of recent findings. Polar Biol 29:1-22

Siegel V, Reiss CS, Dietrich KS, Haraldsson M, Rohardt G (2013) Distribution and abundance of Antarctic krill (Euphausia superba) along the Antarctic Peninsula. Deep-Sea Res I 77:63-74

Simmard Y, Lacroix G, Legendres L (1986) Diel vertical migrations and nocturnal feeding of a dense coastal krill scattering layer (Thysanoessa raschii and Meganyctiphanes norvegica) in stratified surface waters. Mar Biol 91:93-105

Smith CR, Mincks S, DeMaster DJ (2006) A synthesis of bentho-pelagic coupling on the Antarctic shelf: food banks, ecosystem inertia and global climate change. Deep-Sea Res II 53:875-894

> Sourisseau M, Simard Y, Saucier FJ (2006) Krill aggregation in the St. Lawrence system, and supply of krill to the whale feeding grounds in the estuary from the gulf. Mar Ecol Prog Ser 314:257-270

Sourisseau M, Simard Y, Saucier FJ (2008) Krill diel vertical 
migration fine dynamics, nocturnal overturns, and their roles for aggregation in stratified flows. Can J Fish Aquat Sci 65:574-587

Steinberg DK, Ruck KE, Gleiber MR, Garzio LM and others (2015) Long-term (1993-2013) changes in macrozooplankton off the Western Antarctic Peninsula. Deep-Sea Res I 101:54-70

Tarling GA, Thorpe SE (2014) Instantaneous movement of krill swarms in the Antarctic Circumpolar Current. Limnol Oceanogr 59:872-886

Tarling GA, Matthews JBL, Saborowski R, Buchholz F (1998) Vertical migratory behavior of the euphausiid, Meganyctiphanes norvegica, and its dispersion in the Kattegat Channel. Hydrobiologia 375-376:331-341

Tarling GA, Klevjer T, Fielding S, Watkins J and others (2009) Variability and predictability of Antarctic krill swarm structure. Deep-Sea Res I 56:1994-2012

Warren JD, Santora JA, Demer DA (2009) Submesoscale distribution of Antarctic krill and its avian and pinniped predators before and after a near gale. Mar Biol 156:479-491

Editorial responsibility: Robert Condon, Wilmington, North Carolina, USA
Wiebe PH, Buri KH, Boyd SH, Morton AW (1976) A multiple open/closing net and environmental sensing system for sampling zooplankton. J Mar Res 34:313-326

Wiebe PH, Morton AW, Bradley AM, Backus RH and others (1985) New development in the MOCNESS, an apparatus for sampling zooplankton and micronekton. Mar Biol 87:313-323

Wiebe PH, Ashijian CJ, Gallager SM, Davis CS, Lawson GL, Copley NJ (2004) Using a high-powered strobe light to increase the catch of Antarctic krill. Mar Biol 144:493-502

Zhou M, Dorland RD (2004) Aggregation and vertical migration behavior of Euphausia superba. Deep-Sea Res II 51: 2119-2137

- Zhou M, Nordhausen W, Huntley M (1994) ADCP measurements of the distribution and abundance of euphausiids near the Antarctic Peninsula in winter. Deep-Sea Res I 41:1425-1445

Zhou M, Zhu Y, Tande KS (2005) Circulation and behavior of euphausiids in two Norwegian sub-Arctic fjords. Mar Ecol Prog Ser 300:159-178

Submitted: June 30, 2015; Accepted: May 12, 2016

Proofs received from author(s): June 10, 2016 